\title{
A Novel Kind of Activated Carbon Foam Electrode for Electric Double Layer Capacitors
}

\author{
Peng Chang ${ }^{1}$, Zhihong Qin ${ }^{2, *}$ \\ ${ }^{1}$ School of Chemical Engineering and Technology, China University of Mining \& Technology, \\ Xuzhou 221116, China \\ ${ }^{2}$ Key Laboratory of Coal Processing and Efficient Utilization (Ministry of Education), Xuzhou \\ 221116, China \\ *E-mail: qinzh1210@163.com
}

doi: $10.20964 / 2017.03 .29$

Received: 7 December 2016 / Accepted: 12 January 2017 / Published: 12 February 2017

In this paper, a novel kind of activated carbon foam (ACF) electrode for electric double layer capacitors (EDLCs) was prepared by a $\mathrm{KOH}$ activation procedure on primary carbon foams synthesized via foaming of loose medium component (LMC) which was separated from raw coal by extraction and back-extraction processes and then studied electrochemically using cyclic voltammetry. With the aim of exploring the optimum experimental conditions, the influences of process variables, such as foaming temperature, activation temperature, activation time and $\mathrm{KOH} /$ carbon mass ratio on specific capacitance of ACFs were investigated. The morphology, structure and textural properties of the optimum ACF were characterized with $\mathrm{N}_{2}$ adsorption technique, Raman spectrometer, scanning electron microscopy, transmission electron microscopy and X-ray photoelectron spectrometer. The electrochemical behaviors were analyzed by cyclic voltammetry, galvanostatic charge-discharge cycling and electrochemical impedance spectroscopy. The obtained results show that under the optimum experimental conditions, the sample possesses the specific surface area of $3526.31 \mathrm{~m}^{2} \mathrm{~g}^{-1}$, total pore volume of $1.972 \mathrm{~cm}^{3} \mathrm{~g}^{-1}$ and exhibits the highest initial specific capacitance of $204.17 \mathrm{~F} \mathrm{~g}^{-1}$ at current density of $1 \mathrm{~A} \mathrm{~g}^{-1}$ in $6 \mathrm{M} \mathrm{KOH}$ solution. It shows excellent cycling stability with a capacitance retention of $97.9 \%$ after 3000 charge/discharge cycles at current density of $1 \mathrm{~A} \mathrm{~g} \mathrm{~g}^{-1}$, promising its practical application in EDLCs. Thus, the favorable capacitive performances make the ACFs act as a new kind of carbonaceous electrode material for high-power supercapacitors.

Keywords: activated carbon foam; loose medium component; electric double layer capacitors; optimum experimental conditions

\section{$\underline{\text { FULL TEXT }}$}


(C) 2017 The Authors. Published by ESG (www.electrochemsci.org). This article is an open access article distributed under the terms and conditions of the Creative Commons Attribution license (http://creativecommons.org/licenses/by/4.0/). 